\title{
Graduate Students' Emotions and Achievement in Statistics
}

\author{
Somayeh Ghaderizefreh, Michael L. Hoover \\ Department of Educational and Counselling Psychology \\ McGill University, Canada
}

\begin{abstract}
Despite the importance of statistics courses for social science students, many find these courses formidable obstacles to the completion of their degrees and report high levels of anxiety about these courses. Understanding the attitudinal factors among students can help instructors improve both students' attitudes toward statistics and their achievement in statistics courses. In this paper, using Pekrun's control-value theory of achievement emotions, we treat emotions as a central component of students' attitudes toward statistics. To investigate the relations between students' attitude components and achievement in statistics, twenty-nine graduate students in a required statistics class completed questionnaires concerning their academic emotions, which were used to determine which emotions had effects on their academic achievement. Results indicate that students' emotions regarding statistics are more complex than simply feeling anxious, and that these graduate students differed in significant ways from undergraduates in how their academic emotions affected their academic engagement.
\end{abstract}

\section{Introduction}

Statistics is a requirement for social sciences students, providing them necessary skills for understanding, interpreting, and conducting research. However, students often see statistics courses as barriers to the completion of their degrees, and report high levels of anxiety about these required courses [1]. Researchers [2] have argued that for students to succeed, they need to hold positive attitudes toward statistics. Therefore, understanding the antecedents and effects of students' attitudes toward statistics is important to maintain and increase students' positive attitudes.

Although attitude plays an important role in statistics achievement and students' ability to apply statistical knowledge outside the classroom [2], [3], there is not a consensus about the definition of the construct of attitude. Some researchers consider attitudes to be more emotional than cognitive while others consider it to be more like beliefs [4]. However, most believe that attitude is a multidimensional concept referring to positive or negative responses toward statistics [4]. A variety of attitude components (e.g., value, anxiety, fear, cognitive competence, expectancy of success, affect, and interest) have been used to assess the relationship between students' attitudes toward statistics and their achievement. Schau [3] argued that there are causal relationships between the attitude components and statistics achievement that can be represented using a causal model. Researchers have used personal teaching experiences, second language learning theories [5], the results of previous studies [6], and Eccles and colleagues' expectancyvalue theory [7] to develop statistics attitude models that describe the relationships between attitude components and statistics achievement.

Most studies that used Eccles and colleagues' expectancy-value theory tested four or six attitude components measured by the "Survey of Attitudes Toward Statistics" (SATS-28 [8] and -36 [3]). The SATS-28 uses 28 items to measure four attitude components: affect, value, difficulty, and cognitive competence. Based on Eccles and colleagues' expectancy-value theory [7], SATS-28 was revised to create the SATS-36, which includes two additional components: effort and interest.

Sorge and Schau [9] were the first to use the expectancy-value theory to create and test their "Statistics Attitudes-Achievement Saturated Model". This model proposed that previous performance is related to statistics achievement through four attitude components: difficulty, cognitive competence, affect, and value. They found that previous performance and affect were directly associated with statistics achievement. Furthermore, previous performance and difficulty were indirectly related to achievement through cognitive competence and then affect. However, the findings indicated that value was not related to achievement.

Tempelaar, Loeff, and Gijselaers [10] used a large sample $(n=1618)$ of business and economic students in the Netherlands to test the effects of students' attitudes toward statistics on statistical reasoning abilities. They found that value, difficulty, and effort influenced statistical reasoning abilities, while difficulty and cognitive competence affected performance in statistics.

Emmioglu [11] modified and tested Sorge and Schau's [9] model by adding "interest" and "effort" components and used prior mathematics achievement instead of prior statistics achievement. Her sample 
consisted of 247 undergraduate and graduate students enrolled in statistics courses in Turkey. She reported that all attitude components, except difficulty, influenced statistics achievement, while mathematics achievement had a direct effect on statistics achievement.

Hood and colleagues [12] excluded the "interest" factor and added the "expectancies of success" factor to their model of the relationship between attitudes toward statistics and achievement. In this model, as in Sorge and Schau's model [9], previous statistics performance was used to predict statistics achievement. They found that past performance is related to statistics achievement, affect, and cognitive competence; cognitive competence is associated with higher expectancy and value; and expectancy and effort are directly associated with achievement. However, the findings indicated that there were no relationships between past performance and difficulty, affect and value, and value and statistics achievement.

In summary, Eccles and colleagues' expectancyvalue theory has been used in some studies to examine the relationship between attitudes toward statistics and achievement with samples varying in nationality, grade level, and program. All of these studies found that previous achievement (mathematics or statistics) and students' attitudes toward statistics were important predictors of statistics achievement. However, these findings do not indicate the same path between attitude components and statistics achievement. Furthermore, these studies argued that their findings did not support all aspects of the expectancy-value theory.

The most puzzling disagreement between the findings of these studies and the expectancy-value theory was the lack of a relationship between value and statistics achievement. Hood and colleagues [12] as well as Sorge and Schau [9] argued that other researchers also failed to find a path from value to achievement in mathematics and statistics [5]. Hood and colleagues [12] believed that this inconsistency was not a function of a particular sample or specific domain of interest.

The other finding that was inconsistent with the expectancy-value theory was the direct relationship between cognitive competence and affect [9], [10], [11] and [12]. According to Hood and colleagues [12], "these ... studies suggest that at least some types of goals and general self-schema are related to affective reactions, something not currently included in the EVM [Expectancy-value model]" (p. 82).

The literature has shown that researchers and educators need a comprehensive theory to examine the relationships between individual attitude components and statistics achievement. The existing studies also fail to tell us anything about the factors that influence students' attitudes to improve their achievement in statistics. Furthermore, most studies in this field have indicated that affect (student's feelings about statistics such as enjoyment and anxiety) is a strong predictor of statistics achievement [11]. Therefore, it seems that the control-value theory of achievement emotions provides a better understanding of students' attitudes toward statistics and their statistics achievement. The aim of this study is to explore the relationship between students' attitudes toward statistics based on Pekrun's [13] control-value theory of achievement emotions and their academic achievement.

\section{Students' emotions toward statistics}

Recent research has emphasized the importance of academic emotions for achievement outcomes ${ }^{[14]}$. In particular, these studies have emphasized the critical role of emotions in abstract subjects such as mathematics and statistics. Although most research on emotions in statistics has focused on anxiety, students' emotions towards statistics go beyond simply feeling anxious. Pekrun's [13] control-value $(\mathrm{C}-\mathrm{V})$ theory is a framework that emphasizes the centrality of emotions - both positive and negative - in academic settings. $\mathrm{C}-\mathrm{V}$ theory argues that students experience domain-specific academic emotions (e.g., toward mathematics or statistics) that affect their learning and achievement. For example, research on emotions in mathematics indicate that positive emotions such as enjoyment and pride are positively and negative emotions such as boredom, anxiety, anger, and hopelessness are negatively related to mathematics achievement [15]. Also, the theory suggests that control and value appraisals are the proximal antecedents of achievement emotions and that, in turn, achievement emotions influence learning and achievement through cognitive and motivational mechanisms. Based on the theory, individual characteristics (e.g., cognitive abilities and goals), task demands and learning environments are distal antecedents of achievement emotions. These factors can influence students' emotions and consequently their achievement by influencing control and value appraisals.

By using C-V theory, we treat students' emotions as an important attitude component that affect statistics achievement to provide a model of students' attitudes toward statistics (Figure 1). The model proposes that students' emotions toward statistics activities and outcomes, such as enjoyment and anxiety, influence students' involvement in statistics tasks and their motivation to pursue (effort), and consequently their statistics achievement. According to the model, students' perceived value of statistics activities and outcomes influence their emotions. Statistics activities and outcomes can be valued intrinsically (e.g., as being interesting) and 


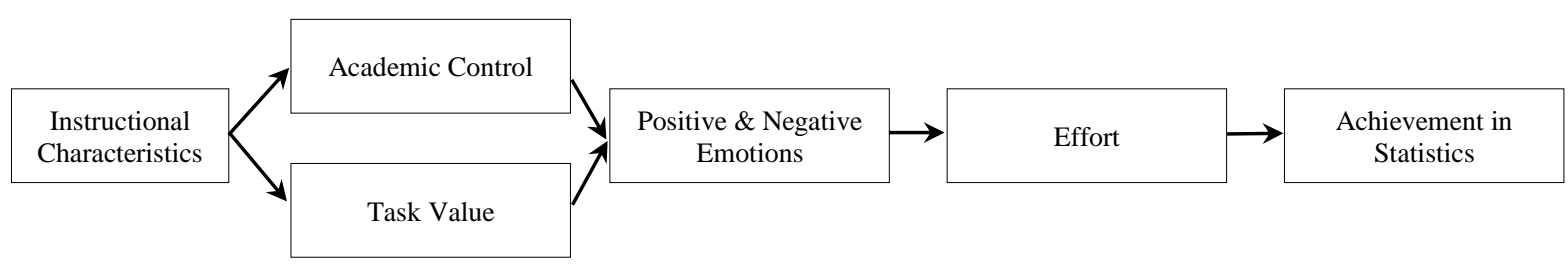

Figure 1. Control-value model for students' attitudes toward statistics [13]

extrinsically (e.g., for being important to understand and conduct research). Furthermore, students' perceived control over statistics activities and outcomes influences their emotions. When students perceive that they are able to successfully complete their statistics courses or when they expect that their efforts will lead to desired outcomes they will experience more positive emotions. In addition, perceiving high competence in statistics and having high expectancy for success decrease students' negative emotions.

According to Pekrun's [13] C-V theory of achievement emotions, the learning environment is an important distal antecedent of students' emotions. He proposes that the following environmental factors influence students' value, control and emotions: (1) cognitive quality and task demands, (2) value induction and the motivational quality of instruction, (3) autonomy support, (4) achievement goal structures and achievement expectations, (5) feedback and consequences of achievement. Some researchers examine teachers' instructional characteristic as an environmental factor, which influences students' emotions. For example, Becker and colleagues [16] state that practical relevance (value-induction) along with understandability and lesson structure (control-induction) are important facets of instructional characteristic that are related to control and value appraisals as well as emotions.

In this study, based on the control-value theory and previous research, it is hypothesized that (1) teachers' instructional characteristic positively relate to enjoyment and negatively relate to anxiety, boredom, and anger; (2) academic control positively relates to enjoyment and negatively to anxiety, anger, and boredom; (3) task value positively relates to enjoyment, and negatively relates to anxiety, boredom, and anger; (4) enjoyment, a positive activating emotion, will positively predict effort and achievement; (5) anxiety and anger, negative activating emotions, as well as boredom, a negative deactivating emotion will negatively predict effort and achievement.

\section{Method}

\subsection{Participants}

Participants were recruited from 60 students enrolled in a required introductory statistics course for a masters of education degree program at a university in Canada. Any student who had passed two undergraduate statistics courses was excluded. 53 students agreed to participate in the study of whom 29 (27 female, 2 male) completed all questionnaires, and were included in the analyses. The mean age of the participants was 26.31 years $(\mathrm{SD}=4.11$, range 22-41).

\subsection{Measures}

A series of questionnaires were adapted from published research to measure students' perception of statistics (task value and control value), their academic emotions, and their perception of the teacher's instructional characteristic and their own effort in the course.

The following two scales were presented at the beginning of the course to measure students' ideas about statistics before they had experienced the course:

Academic control. Perceive control was assessed with modified eight-item Perry, Hladkyj, Pekrun, and Pelletier' [17] Academic Control Scale (e.g., "I have a great deal of control over my academic performance in my statistics course"). Items are scored on a 7-point Likert-type scale ranging from Strongly disagree (1) to Strongly agree (7). The scale included four negatively worded items which were reverse coded for analysis.

Task value. Pintrich et al.'s [18] six-item MSLQ scale was adapted to measure students' perception of the value of statistics. The scale evaluates students' perception of the course's importance, usefulness, and interest. The items were scored on a 7-point Likert scale (Strongly disagree $=1$ and Strongly agree $=7$ ).

Four subscales concerning academic emotions were presented to students after the midpoint of the semester to measure the academic emotions they were experiencing.

Academic emotions. These four subscales were adapted from the Achievement Emotions Questionnaire developed by Pekrun, Goetz, and Frenzel [19] to assess students' emotions. A fouritem enjoyment subscale, a three-item boredom subscale, a four-item anxiety subscale, and a fouritem anger subscale assessed students' class-related emotions. Students rate their emotions in a seven 
point Likert scale from Strongly disagree (1) to Strongly agree (7).

Two further scales were completed by students after the course had ended to measure the amount of work that students spend to learn statistics and their perception of the teacher's instructional characteristic.

Effort. Adapted from five-item Intrinsic Motivation Inventory scale (IMI) developed by McAuliey and colleagues [20]. Items were answered on a 7-point Likert-type scale ranging from Strongly disagree (1) to Strongly agree (7). Higher scores indicated that students devoted greater effort in learning statistics. Two negatively worded items were reverse coded for analysis.

Teacher instructional characteristics. Students' perceptions of their teachers' instructional characteristic were measured using an adapted version of Becker et al.'s [16] scale. The scale includes three items (e.g., "In this course, my teacher explains things in comprehensible way.") which measure three instructional characteristics: practical relevance, understandability, and lesson structure. Items are scored on a 7-point Likert-type scale ranging from Strongly disagree (1) Strongly agree (7).

\section{Procedure}

Students completed questionnaires online, using LimeSurvey software, at three points during the course: the beginning of the semester (demographic questions, academic control, and task value), middle of semester (emotions), and end of semester (instructional characteristic and effort). Students' final mark was matched to their questionnaire results using their student number, at which point all identifying information, including student number, was deleted from the file to ensure confidentiality.

\section{Results}

In the following section, the results of correlation and regression analyses are reported.

Teacher's instructional characteristic and emotions. Students' ratings of teacher's instructional characteristic were correlated with the academic emotions that they experienced in class. Neither boredom, enjoyment nor anxiety were affected by instructional characteristics, however, there was a negative correlation between instructional characteristic and the experience of anger $(r=-.48, p$ $<.01)$, indicating that students who perceived their teacher' instruction as more understandable, saw the practical relevance of the subject matter, and understood the goals of the lessons experienced less anger or frustration.

Academic control and emotions. Parallel to the results on instructional characteristic, only anger was affected by students' perception of academic control $(\mathrm{r}=-.57, \mathrm{p}<.01)$, indicating that students who felt that they had greater control over their performance experienced less anger or frustration about the class.

Task value and emotions. We had predicted, based on the model, that when students valued statistical knowledge, they would experience greater positive and less negative emotions concerning statistics. Consistent with this hypothesis, there was a negative correlation between task value and anxiety $(r=-.43$, $\mathrm{p}<.05)$, indicating that students who valued statistics more highly tended to experience lower levels of anxiety. However, task value had no effect on any other academic emotion.

Emotions and effort. A multiple regression was conducted to determine if effort can be predicted by the four types of emotions. The overall regression model was significant $[R=.71, F(4,24)=5.75, p<$ $.002]$. Together, the four emotions explained $50 \%$ of the variance in effort $\left(R^{2}=.50\right)$. Consistent with our prediction, greater boredom led to less effort $(b=$ $1.57, S E=.40)$. However, contrary to the model's predictions, greater enjoyment $(b=-.63, S E=.23)$ also led to less student effort. Neither anxiety nor anger were a significant predictor of effort on its own. This result indicates that while students who reported being bored with statistics reported less effort, students who reported enjoying statistics also reported spending less effort on the course.

Emotions and achievement. A multiple regression was conducted in order to determine if achievement was predicted by the academic emotions of enjoyment, anger, boredom, and anxiety. The overall regression model was significant, $[R=.70, F(4,24)$ $=5.68, p<.002]$, the four emotions together explained approximately $49 \%$ of the variance in achievement $\left(R^{2}=.49\right)$. High enjoyment $(b=.89, S E$ $=.35)$ and low anxiety $(b=-.57, S E=.22)$ were significant predictors of academic achievement, consistent with previous research and our predictions. Neither anger nor boredom were a significant predictor of achievement on its own.

Effort and achievement. The results from the multiple regressions predicting effort and achievement gave rise to a surprising result that low enjoyment was predictive of high effort (and vice versa); at the same time high enjoyment was predictive of high marks. This seemed to imply contrary to all predictions - that less effort resulted in higher marks. This implication was tested directly 
by calculating the correlation between effort and final mark in the course, which was in fact negative and significant $(\mathrm{r}=-.45, \mathrm{p}<.05)$, indicating that students who expended greater effort earned lower marks. This result contradicts both the predictions of the model and much previous research, which has demonstrated that greater effort leads to higher marks.

\section{Discussion}

The present study, using control-value theory as a framework, investigated the role of academic control, task value and the teacher's instructional characteristic on students' emotions in a graduate statistics class, and the effect of these emotions on their effort and achievement. These results are, in general, consistent with the model proposed, in that students' rating of teacher's instructional characteristic, task value, and sense of control affected their academic emotions, and that academic emotions affected both their effort and achievement in the course. However, not all academic emotions played into each step of the model.

Anxiety. Anxiety has been identified by much research as the emotion of concern in statistics. However, in our results, although anxiety was affected by perceived task value, it was unaffected by instructional characteristic or the student's sense of task control. Furthermore, while higher anxiety was associated with lower achievement, it did not affect the effort that students put into the course.

Boredom. Boredom was unaffected by instructional characteristic, perceived task value, or task control, however students who reported greater boredom put less effort into their work, but boredom was not related to their achievement in the course

Anger. Anger (or frustration) was the emotion most affected by the precursor variables. Students who rated the teacher more negatively experienced greater anger (or frustration), as did those who reported less task control. However, anger did not affect either the effort devoted to the course, nor students' achievement in the course.

Enjoyment. Enjoyment was not affected by any of the precursor variables: teacher's characteristics, task value, or sense of academic control. However, enjoyment was a significant predictor of achievement: students who reported greater enjoyment earned higher marks. Contrary to our predictions and to prior research, greater enjoyment was associated with lower reported levels of effort in the class.

This last result may be the key to understanding the surprising result that, for these graduate students, less effort is related to higher achievement. The students who found the course enjoyable may have been those for whom it required less effort: they 'got' statistics, whereas the students who struggled and had to exert more effort to master the material enjoyed it less, and received lower marks. It is perhaps significant that all of the students in our sample received a grade of $\mathrm{B}$ or better in the course, suggesting that the students who found themselves struggling reacted by devoting more effort to the class in order to ensure that they passed it, as it was a requirement for their masters program. This is in contrast to studies of undergraduate and high school students who, when faced with material with which they struggle, reacted by devoting less effort. The differences between other students and these graduate students may be one of motivation. Graduate students who found the material difficult did not give up, instead they worked harder.

\section{Limitation and future research}

There are several limitations which are important to consider and may be used in designing future research. Due to the small sample size, no strong generalizations should be made from this single case study. The proposed model of students' attitude toward statistics needs be tested with a larger sample of graduate students.

The results of the present study raise issues for future research, especially whether graduate students have a different mind-set than undergraduate students; specifically, that when faced with challenges, they work more, resulting in greater effort being associated with lower achievement.

\section{Conclusion}

In this study, Pekrun's C-V theory was used to test whether graduate students' emotions toward statistics go beyond feeling anxious. Our findings indicate that emotions other than anxiety affect students' engagement and achievement in statistics. The results, in general, are consistent with the proposed model in that effort and achievement are affected by students' emotions, which in turn are affected by teacher's instructional behavior and the control and value that students assign to the course material.

These findings suggest that teachers should pay attention to their instructional behaviors because these affect students' emotions, which in turn influence both students' effort and achievement.

However, contrary to previous findings, we found that graduate students who struggled with statistics reacted by increasing their effort. The students who put in the least effort were those with higher grades and those who most enjoyed the course, the opposite of the pattern found in previous studies with undergraduates. These findings suggest that graduate students - unlike undergraduates and high school students - are highly achievement-oriented and 
respond to challenging materials by putting in more effort rather than less.

\section{References}

[1] Onwuegbuzie, A.J. (2003) 'Modeling Statistics Achievement Among Graduate Students', Educational and Psychological Measurement, 63(6), pp. 1020-1038.

[2] Mills, J.D. (2004) 'Students' Attitudes Toward Statistics: Implications for the Future', College Student Journal, 38(3), pp. 349-361.

[3] Schau, C. (2003) 'Students' Attitudes: The 'Other" Important Outcome In Statistics Education', In Proceedings Of The Joint Statistical Meetings, pp. 36733681.

[4] Hemmings B, Grootenboer P, \& Kay R. (2011) 'Predicting mathematics achievement: The influence of prior achievement and attitudes', International Journal of Science and Mathematics Education, 9(3), pp. 691-705.

[5] Tremblay, P. F., Gardner, R. C., \& Heipel, G. (2000) 'A model of the relationships among measures of affect, aptitude, and performance in introductory statistics', Canadian Journal of Behavioral Science, 32(1), 40-48.

[6] Chiesi, F., \& Primi, C. (2010) 'Cognitive and noncognitive factors related to students' statistics achievement', Statistics Education Research Journal, 9(1), pp. 6-26.

[7] Wigfield, A., \& Eccles, J. S. (2002) 'The development of competence beliefs, expectancies for success, and achievement values from childhood through adolescence. In A. Wigfield \& J. S. Eccles (Eds), Development of achievement motivation (pp. 91-120). San Diego: Academic Press.

[8] Schau, C., Stevens, J., Dauphinee, T. L., \& Vecchio, A. D. (1995). 'The development and validation of the survey of attitudes toward statistics', Educational and Psychological Measurement, 55(5), 868-875.

[9] Sorge, C. \& Schau, C. (2002) 'Impact Of Engineering Students' Attitudes On Achievement In Statistics: A Structural Model', In Annual Meeting Of The American Educational Research Association, New Orleans.

[10] Tempelaar, D. T., Loeff, S., \& Gijselaers, W. H. (2007) 'A structural equation model analyzing the relationship of students' attitudes toward statistics, prior reasoning abilities and course performance', Statistics Education Research Journal, 6(2), 78-102.

[11] Emmioglu, E. (2011) 'A structural equation model examining the relationships among mathematics achievement, attitudes toward statistics, and statistics outcomes'. (Doctor of Philosophy), Middle East Technical University, Ankara, Turkey.

[12] Hood, M. Creed, P.A. \& Neumann, D.L. (2012) 'Using the Expectancy Value Model Of Motivation to Understand the Relationship Between Student Attitudes and Achievement in Statistics', Statistics Education Research Journal, 11(2), pp. 72-85.

[13] Pekrun, R. (2006) 'The Control-Value Theory of Achievement Emotions: Assumptions, Corollaries, and Implications for Educational Research and Practice', Educational Psychology Review, 18(4), pp. 315-341.

[14] Pekrun, R. \& Linnenbrink-Garcia, L. (2014) 'International Handbook of Emotions in Education', Routledge, 16.

[15] Peixoto, F. Sanches, C. Mata, L. \& Monteiro, V. (2016) 'How do you feel about math?: relationships between competence and value appraisals, achievement emotions and academic achievement', European Journal of Psychology of Education, pp. 1-21.

[16] Becker, E. S., Goetz, T., Morger, V., \& Ranellucci, J. (2014) 'The importance of teachers' emotions and instructional behavior for their students' emotions - An experience sampling analysis', Teaching and Teacher Education, 43, 15-26.

[17] Perry, R. P., Hladkyj, S., Pekrun, R. H., \& Pelletier, S. (2001) 'Action control and perceived control in the academic achievement of college students: A longitudinal field study', Journal of Educational Psychology, 93, 776789 .

[18] Pintrich, P. R., Smith, D. A. F., Garcia, T., \& McKeachie, W. J. (1991) 'A manual for the Motivated Strategies for Learning Questionnaire (MSLQ)', Ann Arbor, MI: National Center for Research to Improve Postsecondary Teaching and Learning.

[19] Pekrun, R., Goetz, T., \& Perry, R. P. (2005) 'Achievement Emotions Questionnaire-Mathematics (AEQ-M): User's manual', Munich, Germany: University of Munich, Department of Psychology.

[20] McAuley, E., Duncan, T., \& Tammen, V. V. (1987) 'Psychometric properties of the Intrinsic Motivation Inventory in a competitive sport setting: A confirmatory factor analysis', Research Quarterly for Exercise and Sport, 60, 48-58. 